\title{
O paradigma indiciário na era da informação: os desafios semióticos do processo penal
}

\author{
The indiciary paradigm in the information era: \\ the semiotic challenges of the criminal process
}

\author{
ELIOMAR DA SILVA PEREIRA* \\ eli.omar.vii@gmail.com
}

GALILEU - REVISTA DE DIREITO E ECONOMIA - e-ISSN 2184-1845

Volume XXI $\cdot 1^{\text {st }}$ July Julho - 31 $1^{\text {st }}$ December Dezembro $2020 \cdot$ pp. 46-56

DOI: https://doi.org/10.26619/2184-1845.XXI.2.3

Submitted on September $28^{\text {th }}, 2020$. Accepted on November $10^{\text {th }}, 2020$

Submetido em 28 de setembro, 2020 . Aceite a 10 de novembro 2020

RESUMO A era da informação, sobretudo em sua expressão digital, tem promovido grande revolução nas relações sociais, viabilizando novas perspectivas interativas nos âmbitos diversos da sociedade, política e economia, assim como no âmbito da criminalidade comum e organizada. Ao passo que cria ambientes novos de prática de antigos crimes, viabiliza também novos crimes que se praticam no espaço cibernético, mas também acaba por criar novos sinais que se podem assimilar como indícios de atividades relevantes à investigação do crime no processo penal. Este artigo tem por objetivo discutir o paradigma indiciário que permanece relevante à compreensão desse universo de sinais digitais, segundo uma abordagem semiótica das provas, bem como delimitar suas possibilidades lógicas fundamentadas em inferências abdutivas, ao passo que reafirma os direitos fundamentais de defesa que em nada devem ser abalados pela multiplicação dessas novas fontes de informação.

PALAVRAS-CHAVE paradigma - informação - índice - abdução - semiótica

ABSTRACT The information age, especially in its digital expression, has promoted a great revolution in social relations, enabling new interactive perspectives in different areas of society, politics and economics, as well as in the scope of common and organized crime. While it creates new environments for the practice of old crimes, it also enables new

\footnotetext{
* Doutor em Direito (Universidade Católica Portuguesa, Escola de Lisboa). Investigador Integrado do Ratio Legis - Centro de Investigação e Desenvolvimento em Ciências Jurídicas, Universidade Autónoma de Lisboa: Corpus Delicti - Estudos de Criminalidade Organizada Transnacional. Professor do Programa de Pós-Graduação da Escola Superior de Polícia (Polícia Federal do Brasil). Delegado de Polícia Federal. Assessor da Casa Civil (Presidência da República do Brasil).
} 
O paradigma indiciário na era da informação: os desafios semióticos do processo penal

ELIOMAR DA SILVA PEREIRA

GALILEU - e-ISSN 2184-1845 - Volume XXI - Issue Fascículo 2 - $1^{\text {st }}$ July Julho - 31 ${ }^{\text {st }}$ December Dezembro 2020 - pp. 46-56

crimes that are practiced in cyber space, but it also ends up creating new signs that can be assimilated as evidence of activities relevant to the investigation of crime in criminal proceedings. This article aims to discuss the evidential paradigm that remains relevant to the understanding of this universe of digital signals, according to a semiotic approach to evidence, as well as to delimit its logical possibilities based on abductive inferences, while reaffirming the fundamental rights of defense that in no way must be shaken by the multiplication of these new sources of information.

KEYWORDS paradigm - information - index - abduction - semiotics

\section{Introdução}

A noção de paradigma já era conhecida no mundo antigo como modelo ou exemplo, conforme se buscasse um padrão no mundo das ideias ou no mundo da experiência ${ }^{1}$, mas foi apenas no século passado que se renovou seu interesse a partir da historiografia das ciência com a obra de Thomas Kuhn, gerando discussões que lhe exigiram melhor explicar-se m Posfácio (1969), para defini-lo inicialmente como aquilo que os membros de uma comunidade cientifica partilham, explicando-o como uma "constelação dos compromissos de grupo" que abrange "generalizações simbólicas", "partes metafísicas", valores e exemplares compartilhados ${ }^{2}$. Diríamos, melhor, contudo, que certos paradigmas podem ser compartilhados por várias comunidades, não apenas científicas, como também jurídicas, a exemplo do paradigma indiciário. E de forma mais sintética, podemos compreender o paradigma como um parâmetro ético-epistêmico de ação e pensamento que inclui uma visão de mundo e do homem. E, nesse sentido, ele terá sempre algumas diversas variações e mesmo um contra-parâmetro que disputa sua validade no âmbito de uma comunidade.

O paradigma indiciário, nesse sentido, embora se refira imediatamente a uma específica epistemologia, que podemos encontrar em várias comunidades, tanto científica quanto jurídica, tem uma face ético-política, cujo contra-paradigma apodítico nos permite compreender melhor o que está em questão e nos interessa discutir no âmbito específico do processo penal.

A civilização ocidental sempre privilegiou o apodítico em detrimento do indiciário, mas nunca o descartou em absoluto, pelo menos como ponto de partida, embora sempre

1 ABBAGNANO, N. - Dizionario di filosofia. Torino: UTET, 2013, p. 792.

2 KUHN, T. S. - Aestrutura das revoluções científicas. São Paulo: Perspectiva, 2009, pp. 219ss. 
buscando afirmar-se ao final como paradigma dominante. O indiciário foi confiscado pelo apodítico, como parte deste que evita colocar-se como seu contrário, para ao final sobrepor-se. Trata-se de uma estratégia cognitiva que acaba por criar uma aparência de rigor crescente, na qual a fase anterior é assimilada pela posterior que se torna superior, dando-nos mais garantias de verdade, embora abaixa da superfície aparente, subsistam as mesmas dúvidas epistemológicas.

Nós o identificamos mais rapidamente em nosso meio jurídico na estrutura do processo penal, em que o indiciário é tomado como necessário, na fase de inquérito - a exemplo do direito português, embora por vezes desconsiderado no direito brasileiro, mas em todo caso nunca considerado como suficiente às conclusões das sentenças. Contudo, em perspectiva epistemológica séria, bem observado e entendido, a sentença permanece indiciária, porque não se obtém uma certeza como se postula pelo discurso jurídico tradicional, embora se tenha acrescido um elemento importante à decisão: a possibilidade de debate que é a face ético-política do mesmo paradigma.

A mesma estrutura de pensamento se encontra no desenvolvimento da ciência. As hipóteses (indiciárias) se consolidam como teoria porque se permitiram discutir sem refutação alcançada, mas não nos dão certezas absolutas, como se tem enfatizado pela epistemologia popperiana que surge no final do século passado e tende a permanecer forte no atual século ${ }^{3}$.

\section{2. $O$ apodítico na tradição filosófica}

Contudo, como o dissemos, a ideia de certeza sempre foi privilegiada, com o paradigma apodítico que se consolidou na civilização ocidental, alcançado sua reafirmação moderna na filosofia de Descartes, cujo espírito more geometrico privilegiava a demonstração como procedimento cognitivo racional em detrimento da argumentação, deixada ao nível da retórica ${ }^{4}$.

O que não fica evidente, mas precisamos entender preliminarmente, é que as estruturas de pensamento apoditicio viabilizam estruturas políticas autoritárias e vice-versa. Essa compreensão se deve ao espírito do racionalismo crítico de Karl Popper, que soube identificar as relações entre os discursos epistêmico e político de Platão, em cuja filosofia identifica elementos autoritários, tanto no Teeteto, que trata da crença verdadeira e justi-

\footnotetext{
3 POPPER, K. - A lógica da pesquisa científica. São Paulo: Cultrix, 1975.

4 PERELMAN, C.; OLBRECHTS-TYTECA, L. - Tratado da argumentação. A nova retórica. São Paulo: Martins Fontes, 2002, pp. 2ss.
} 
ficada, quanto na República, que fala de Reis filósofos, cujas relações não evidentes são o apoio entre um e outro5.

Quando falamos em paradigma apodítico, portanto, precisamos compreender como duas faces do mesmo autoritarismo que se reforçam, um cognitivo e outro potestativo que tendem ao dogmatismo e ao despotismo, o que no processo penal tem consequências sérias aos direitos fundamentais ${ }^{6}$. E, nesse sentido, será oportuno compreender que o paradigma indiciário é o único capaz de conviver com a forma de vida democrática, porque se apresenta como hipótese aberta a outras interpretações, em um universo de valores múltiplos, formas de vida e visão de mundo.

Mas o que é exatamente esse paradigma indiciário?

\section{O paradigma indiciário nos pensamentos científico e penal}

Atribui-se geralmente a Carlo Ginzburg ter cunhado essa expressão no final do século XX, mas para referir-se a um padrão de pensamento que se pode encontrar em tempos imemoriais, desde caçadores que interpretavam os rastos deixados por suas presas ${ }^{7}$. O caçador é, nesse sentido, o tipo primordial de que podemos extrair o padrão básico de pensamento indiciário, no qual o sujeito de conhecimento se utiliza dos sinais de que dispõe, daquilo que consegue rastrear, fazendo interpretações e algumas inferências lógicas para concluir acerca do que lhe interessa, qual presa passou por ali, há quanto tempo e em que direção foi. Algumas conclusões mais indiciárias que outras, mas o suficiente para tomar uma decisão sobre o que fazer em seguida a perseguição.

Mas de forma similar, podemos encontrar o mesmo padrão de raciocínio no médico e no analista de arte. Ambos se orientam por outros tipos de sinais para concluir indiciariamente acerca do que lhes interessa conhecer e decidir. O médico se orienta pelos sintomas que pode constatar por contatos e inquirição do paciente, de cuja percepção depende para obter um relato compatível com seu acervo semiológicos de acordo com uma ciência de base, que nesse ponto exerce a mesma função do senso comum do caçador. O analista de arte, por sua vez, orientando-se por padrões de traços que revelam a personalidade do artista, que fazem de sua obra algo particularmente específico e único em comparação com outras, como uma expressão de sua identidade individual.

5 POPPER, K. - A sociedade aberta e seus inimigos. Belo Horizonte: Itatiaia, 1987.

6 A respeito dessa imbricação entre cognitivo e potestativo, cf. PEREIRA, E. S. - Saber e Poder. O processo de investigação penal. Florianópolis: Tirant Lo Blanch, 2019.

7 GINZBURG, C. - «Sinais: Raízes de um paradigma indiciário». In: Mitos, emblemas e sinais. São Paulo: Companhia das Letras, 1989, pp. 143-180. 
Esse mesmo padrão indiciário de pensamento se desenvolveu na área criminal, em diversas perspectivas por Lombroso, Bertillon e Locard ${ }^{8}$. Cesare Lombroso, em sua antropologia criminal, postulava que certas características físicas poderiam nos revelar personalidades criminosas, teoria esta que embora se tenha alterado, não se abandonou completamente a considerar a obra recente de Adrian Raine, agora focada em sinais genéticos ou funcionamento cerebral acessível por instrumentos de imagem ${ }^{9}$.

Alphonse Bertillon, ainda na lógica da antropometria, desenvolve o sistema de identificação humana por digitais papilares que se tornará potente instrumento de utilização de vestígios deixados pelo criminoso, atualmente potencializado pelos vestígios de DNA no local, acrescido por outras formas individualizantes de sujeitos. Essa ideia fundamental da investigação levou Edmond Locard a postular o "princípio da troca", pelo qual "todo contato deixa uma marca"10, o que poderá ser reformulado para estender-se aos contextos da era da informação. Pelo princípio, um sujeito qualquer, ao praticar atos quaisquer, realiza uma troca por contato com o ambiente, que deixa vestígios que nos permitem chegar a certas conclusões por indícios. Essas inferências tanto se referem a sua identidade, como se defendeu por Bertillon, quanto a características de sus atos ${ }^{11}$. Todas essas argumentações de raciocínio se estabeleceram sobretudo para crimes de homicídio, mas a criminalística se desenvolveu para diversos âmbitos, como vemos na obra de Ceccaldi ${ }^{12}$, podendo atualmente utilizar-se na era da informação.

Trata-se de um padrão epistêmico de pensamento que Gaston Bachelard soube muito bem identificar como forma de conhecimento aproximado ${ }^{13}$ e que C. S. Peirce fundamentou adequadamente em seus estudos acerca da inferência chamada abdução a partir do signo específico chamado índice ${ }^{14}$, que inspirou muitas discussões no âmbito da semiótica, a partir de estudos relativos à lógica da investigação criminal ${ }^{15}$.

8 WEHNER, W. - História de a criminología. Barcelona: Zeus, 1964.

9 RAINE, A. - Anatomia da violência. Porto Alegre: Artmed, 2015.

10 LOCARD, E. - A investigação criminal e os métodos científicos. São Paulo: Saraiva, 1934.

11 THORWALD, J. - El siglo de la investigacion. Barcelona: Labor, 1966.

12 CECCALDI, P. F. - A criminalística. Lisboa: Europa-America, 1988.

13 BACHELARD, G. - Ensaio sobre o conhecimento aproximado. Rio de Janeiro:Contraponto, 2008.

14 PEIRCE, C. S. - Semiótica. São Paulo: Perspectiva, 2017, pp. 32ss, pp. 74ss.

15 ECO, U. e SEBEOK, T. A. - O signo de três. São Paulo: Perspectiva, 2014. 


\section{Os índices da era da informação: sinais digitais}

A era da informação incrementa todo esse universo de possibilidades investigativas, fornecendo-nos sinais diversos que nos indicam algo que nos interessa a respeito do crime ${ }^{16}$. Não se trata de indicações necessariamente imediatas, que nos relatam diretamente o crime, mas nisso continua a seguir-se o padrão indiciário: ainda estamos a tratar de índices segundo a semiótica.

Os diversos sinais decorrem de forma específica da vida que a era da informação nos disponibiliza, mas que de certa forma também no impõe como condicionamento, criando um ambiente de troca, de rastos e vestígios de atividades que apenas representam cotidianos, mas que se podem tornar objeto de investigação. Assim, para ficarmos com apenas três exemplos, podemos falar do sinal de celular, da navegação na internet e das comunicações em redes sociais:

a) Os sinais de celular se podem compreender como uma extensão da identicidade individual, permitindo-nos repensar o argumento do álibi de uma forma diversa que dispensa a testemunha de companhia. O mesmo se pode falar do local de conexão à internet. Mas é necessário observar que, apesar da precisão de informação, este dado nos oferece indícios de que o titular da linha estava com o aparelho, o que precisa ser levado em conta.

b) A navegação na internet deixa vestígios que se podem interpretar como marcas digitais de movimentação, naquele mesmo sentido primordial do caçador, dando-nos informações sobre buscas, compararas e interesses que nos podem revezlar indícios da aquisição de instrumentos para prática do crime investigados, propensões à pedofilia entre outras tantas coisas, a depender do tipo penal. Mas aqui igualmente, como mais razão, essas informações podem se interpretar com indícios de outras tantas possibilidades, representativos de atividades cotidianas comuns a uma variedade de pessoas insuspeitas do crime.

c) O mesmo padrão se vai encontrar nas comunicações em redes sociais que se podem interpretar na linha behaviorista ${ }^{17}$ como sintomas da personalidade, o que pode ser importante indícios para crimes de ódio, assim como para outros todos os casos em que se pode agregar informação acerca da pessoas, visando ao cálculo devido da pena.

16 A respeito do significado da expressão "era da informação", em todas as duas relações com a sociedade, a economia e o crime, cf. CASTELLS, M. - A Era da Informação, Volume 1: A Sociedade em Rede. Rio de Janeiro: Paz\&Terrra, 1999; especialmente, CASTELSS, Manuel - «A conexão perversa: a economia do crime global». In: A era da Informação, Volume 3: O fim do milênio. São Paulo: Paz\&Terra, 2009, pp. 203-249.

17 SKINER, B. F. - Sobre o behaviorismo. São Paulo: Cultrix, 2011. 


\section{Sinais, entre prova e indício}

O fundamental nesses casos da era da informação, mais do que nunca, será ter uma clara distinção entre prova e indício, tendo sempre o fato em vista, o que muitos manuais ainda insistem em desorientar, distinguindo-os numa perspectiva equivocada. Afinal, a prova não se distingue do indício como elemento materialmente separado; não se trata de duas coisas necessariamente. Um único objeto possui propriedades informáticas que nos permitem inferir várias coisas a respeito dele, algumas em caráter indiciário, outros em caráter probatório, mas mesmo nesse caso, a depender do estágio de acordo que existe acerca do sinal de informação. O que os distingue, portanto, será o grau de probabilidade com que estamos dispostos a aceitá-los.

Em grande medida, essa probabilidade depende muito do tipo de inferência lógica que fazemos a partir do que temos. Rigorosamente, a prova mesmo, só a teríamos nos casos dedutivos puros, mas cuja premissa maior não seja discutível em algum nível, o que nem sempre é o caso para contextos de interesse de conflitos, como é o âmbito do processo penal. É que muitas premissas maiores são dependentes verdadeiramente do tanto de casos específicos que se colheram para produzirmo-las, sendo aqui necessário falar em probabilidade indutiva da premissa maior.

A questão é que a maior parte das inferências lógicas que nos interessam mais diretamente na investigação criminal são do tipo abdutivo ${ }^{18}$, que se impõe como conclusões indiciárias irremediavelmente, e a respeito disso a sentença não incremente nada além da oportunidade ético-política de discutir o quão logicamente abdutiva são s as inferências suscitadas pela investigação.

A discussão indiciária a respeito das informações obtidas, nesse sentido, instaura um jogo de disputa semiótica, acerca dos significados que os sinais obtidos representam na constituição tépida do crime. E aqui se situa o ambiente de desafio da investigação criminal na era da informação. A autoridade investigante, seus agentes e peritos, têm o papel fundamental de atribuir significados indiciários, interpretando as informações obtidas na investigação, em um jogo do tipo inicialmente similar a um quebra-cabeças, reforçando cada sentido de uma peça com a concordância de outras que se vão ajustando em uma imagem coerente que se posas sustentar em uma argumentação na disputa semiótica.

É extremamente importante ao processo penal colocar-se nessa dimensão semiótica de disputa de atribuição de significados típicos às informações obtidas, porque estas comunicam muitas coisas diversas do que interessa ao ambiente criminal. Afinal, no atual estágio 
criminológico das organizações criminosas, a divisão de tarefas admite que um componente realize ações de suporte que são à primeira vista atividades cotidianas, corriqueiras mesmo, que dificilmente se percebem como criminosas imediatamente. Em outras palavras, eles têm a aparência de legalidade, a superfície das relações sociais, mas em um estrato mais abaixo de percepção fenomenológica, eles se podem apresentar como indícios de participação na organização. Atribuir significados típicos a essas informações constitui verdadeiro exercício de engenharia semiótica que se pode muito facilmente perder em ilações poucos razoáveis, pouco prováveis, pouco aceitáveis ou sem qualquer sentido mesmo.

O desafio, portanto, em última análise, está na exigência natural a investigação, que requer do investigador hipótese sempre mais criativas, mas que ele mesmo deve acautelar-se com a consciência de que são conjecturas, refutáveis sempre, que não se podem antecipar e impor à revelia do direito de defesa, que nesse caso se habilita como uma outra possível atribuição semiótica de significação.

$E$, nesse sentido, a era da informação, embora inove em diversidade de possibilidades de obtenção de prova, além de inovar sobre os meios de prova, apenas renova a tradicional exigência de garantia dos direitos fundamentais no direito penal ${ }^{19}$, e em especial os direitos de defesa no processo penal ${ }^{20}$.

Esses direitos de defesa podem vir sob diversas formas, mas algumas se podem antecipar pela investigação, visando a evitar problemas jurídicos recorrentes. O problema dos falsos perfis nos remete à negação da identidade. Não se trata de um problema absolutamente novo e típico da era da informação, a considerar as identidades falsas para saque de FGTS e benefícios previdenciários fraudulentos, mas os falsos perfis se tornaram muito mais fáceis de criar do que a produção de uma nova identidade física. Atualmente proliferam perfis falsos, em vários sites, aplicativos e base de dados informáticos, que se utilizam pelo agente criminoso, mas identificação neste caso se transfere a outros dados de que dificilmente se pode desvencilhar sem a colaboração de um terceiro. Contudo, as possibilidades de incerteza subsistem, devendo merecer cautela da investigação sempre que o terminal possa ser de utilização coletiva ou mesmo compartilhada, embora os aparelhos com acesso por digital papilar tendam a minimizar essa dúvida. Mas mesmo nesses casos há possibilidades de dissociação entre a identificação digital de acesso e a identicidade de

19 Aqui se justificam as advertências de RODIGUES, A. M. - «Inteligência Artificial no Direito Penal - a Justiça Preditiva entre a Americanização e a Europeização». In: RODRIGUES, A. M. (Org.). A Inteligência Artificial no Direito Penal. Coimbra: Almedina, 2020, ao observar que: "O processo digital verificou-se sem haver confronto entre ciência computacional, liderando a revolução digital, e os especialistas em direito penal".

20 A respeito, são relevantes as questões jurídicas reafirmadas por BELEZA, T. P. e COSTA PINTO, F. L. - Prova criminal e direitos de defesa. Estudos sobre a teoria da prova e garantias de defesa em processo penal. Coimbra: Almedina, 2013. E, com maior razão, torna-se então cada vez mais relevante. 
quem realizou a navegação, salvo se tivermos algum registro de imagem com que possamos aproximar melhor de alguma certeza, embora levando em conta a necessidade de confirmação da pessoa da imagem, tendo em consideração casos de erros recentes sobre a prisão de homem que tinha alguns muitos centímetros a menos do que a imagem captada, apesar das similaridades inicialmente indiciárias.

O problema do acesso às fontes abertas, por sua vez, continuará gerando as mesmas dúvidas de credibilidade da prova obtida na investigação criminal sem o controle recíproco das partes em contraditório. $O$ fato de que se apresentam por veículos de materialidade digital, colhida no mundo virtual, não exclui a dúvida sobre o local de obtenção e sua relação com o autor imputado, podendo exigir-se uma auditoria pericial que dê conta da cadeia de obtenção e transmissão dessa prova, atestando o que se diz a respeito da fonte. Esse é um problema recente que se suscitou a respeito das interceptações de comunicações por terceiro que disponibilizou para meio de comunicação, embora se trate de fontes que juridicamente seriam restritas.

Mas aqui ressurge a mesma questão sempre acerca dos testemunhos periciais apresentadas por um documento, como há tempos Nicola F. Dei Malatesta nos advertia em sua lógica das provas ${ }^{21}$. O universo de provas, por mais variedades de formas que se possam encontrar, mesmo na era da informação, em seu conteúdo se resumem a testemunhos e documentos, e esses se reconduzem sempre à produção humana segundo seus interesses de momento; e quanto aos objetos, que nunca falam por si, exigem que nós falemos algo sobre eles, por testemunha ou documentos, ainda que estes se habilitem como expertos, é sempre uma opinião subjetiva, de alguém sobre algo. Em resumo, reafirmando, uma disputa semiótica de atribuição de sentidos a certos sinais. A esse respeito, basta que pensemos no objeto perfeito por excelência no mundo da investigação criminal - o copo de um morto, que pedirá que alguém fale por ele.

E mesmo as fontes restritas e controladas, na era da informação, não se livram dessa limitação indiciária, afinal a questão dessas fontes está no objetivo de proteção aos seus conteúdos - geralmente em garantia da intimidade das comunicações, apesar da extensão promovida pelo marco civil da internet no Brasil. Mas quanto à credibilidade da informação, muito pouco se acresce em relação às fontes abertas, mantendo assim seu caráter indiciário, a considerar que, do ponto de vista lógico, em razão da intermediação por mais um sujeito, que detém a informação, precisamos inferir que ele nos disponibiliza todas, sem alteração, acréscimo ou exclusão, em síntese sem interesse direto no caso criminal, 
o que ao final vai sempre nos exigir um controle da cadeia de custódia da prova ${ }^{22}$, cujos princípios lógicos tendem a exigir do direito probatório contemporâneo a assimilação de específico princípio jurídico cada vez mais relevante à era das informações digitais.

\section{Considerações finais}

Os desafios processuais da investigação criminal, na era da informação, embora se tenha obtido o incremento de fontes informáticas, persistem sendo os mesmos de sempre que se encontram na lógica do raciocínio indiciário, com suas potencialidades de descoberta e suas limitações de justificação fundada em abduções. São desafios semióticos. Nada há com que se espantar nessa constatação redutora da diversidade aparente de novas provas. Essa é a lógica humana subjacente com que precisamos enfrentar as diversas questões da vida que se nos apresentam, nos domínios virtuais da internet e suas redes sociais que postulam ser o intermediador contemporâneo do acesso aos domínios da realidade. Nada há de novo igualmente nisso, a considerar a estrutura semiótica da cultura humana, construída sobre signos diversos, do mito à ciência, passando pela intermediação sempre frequente da linguagem, mas sempre voltando a encarnar o espírito mítico em outras formas simbólicas, aparentemente depuradas pela razão que apenas se embrenha nos seus próprios labirintos ${ }^{23}$.

Mas nisso, portanto, não estará sozinho o processo penal, nos tempos líquidos das informações fugidias que em todo sítio nos podem enganar, não apenas nos sites virtuais, apresentando apenas a superfície das essências que a fenomenologia sonha encontrar antes das objetivações científicas ${ }^{24}$, mas que a filosofia antiga sempre defendeu ser inacessível, ao postular a ilusão do mundo, envolta por um véu de ignorância que alicia os sentidos daquele que pretende enfrentar a vida apenas com os sentidos da visão, sem atentar para os sentidos da vida ${ }^{25}$.

22 A respeito, torna-se cada vez mais fundamental a discussão jurídica que promove com rigor GUEDES VALENTE,

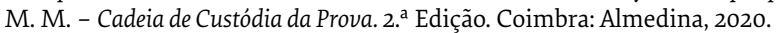

23 A respeito das diversas formas simbólicas com que o home vive e convive, como animal symbolicum, é fundamental a obra de CASSIRER, E. - A Filosofia das Formas Simbólicas. São Paulo: Martins Fontes, 2001 (Primeira parte - A linguagem), 2004 (Segunda parte - O pensamento mítico), 2011 (Terceira parte) - Fenomenologia do conhecimento), bem como a sua síntese posterior CASSIRER, E. - Ensaio sobre o Homem. Introdução a uma filosofia da cultura humana. São Paulo: Martins Fontes, 2001.

24 HUSSERL, E. - A ideia de fenomenologia. Lisboa: Edições 70, 2007.

25 ELIADE, M. - Yoga. Liberdade e imortalidade. São Paulo: Pallas Atena, 1996. 


\section{REFERÊNCIAS BIBLIOGRÁFICAS}

ABBAGNANO, Nicola - Dizionario di filosofia. Torino: UTET, 2013.

BACHELARD, G. - Ensaio sobre o conhecimento aproximado. Rio de Janeiro: Contraponto, 2008.

BELEZA, T. P. e COSTA PINTO, F. L. - Prova criminal e direitos de defesa. Estudos sobre a teoria da prova e garantias de defesa em processo penal. Coimbra: Almedina, 2013.

BONFANTINI, M. A. e PRONI, G. - «Suposição: Sim ou Não?, Eis a Questão». In: ECO, U. e SEBEOK, T. A. (Org). O signo de três. São Paulo: Perspectiva, 2014, pp. 131-148.

CASTELLS, M. - Aera da informação, Volume 1. A sociedade em Rede. Rio de Janeiro: Paz\&Terra, 1999.

CASTELSS, Manuel - Aera da Informação, Volume 3: O fim do milênio. São Paulo: Paz\&Terra, 2009.

CASSIRER, E. - A Filosofia das Formas Simbólicas. São Paulo: Martins Fontes, 2001 (Primeira parte - A linguagem), 2004 (Segunda parte - O pensamento mítico), 2011 (Terceira parte - Fenomenologia do conhecimento).

CASSIRER, E. - Ensaio sobre o Homem. Introdução a uma filosofia da cultura humana. São Paulo: Martins Fontes, 2001.

CECCALDI, P. F. - Acriminalística. Lisboa: Europa-América, 1988.

ECO, U. e SEBEOK, T. - O signo de três. São Paulo: Perspectiva, 2014.

ELIADE, M. - Yoga. Imortalidade e Liberdade. São Paulo: Pallas Atena, 1996.

GINZBURG, C. - Mitos, emblemas e sinais. São Paulo: Companhia das Letras, 1989.

GUEDES VALENTE, M. M. - Cadeia de Custódia da Prova. 2. ${ }^{a}$ Edição. Coimbra: Almedina, 2020.

HUSSERL, E. - Aideia de fenomenologia. Lisboa: Edições 70, 2007.

KUHN, T. - Aestrutura das revoluções científicas. São Paulo: Perspectiva, 2009.

LOCARD, E. - A investigação criminal e os métodos científicos. São Paulo: Saraiva, 1934.

MALATESTA, N. F. Dei - A Lógica das provas em matéria criminal. Campinas: Bookseller, 1996.

PEIRCE, C. S. - Semiótica. São Paulo: Perspectiva, 2017.

PEREIRA, E. S. - Saber e Poder. O processo de investigação penal. Florianópolis: Tirant Lo Blanch, 2019.

PERELMAN, C. e OLBRECHTS-TYTECA, L. - Tratado da argumentação. A nova retórica. São Paulo: Martins Fontes, 2002.

POPPER, K. - A lógica da pesquisa científica. São Paulo: Cultrix, 1975.

POPPER, K. - A sociedade aberta e seus inimigos Belo Horizonte: Itatiaia, 1987.

RAINE, A. - Anatomia da violência. Porto Alegre: Artmed, 2015.

RODIGUES, A. M. - «Inteligência Artificial no Direito Penal - a Justiça Preditiva entre a Americanização e a Europeização». In: RODRIGUES, A. M. (Org.). A Inteligência Artificial no Direito Penal. Coimbra: Almedina, 2020.

SKINER, B. F. - Sobre o Behaviorismo. São Paulo: Cultrix, 2011.

THORWALD, J. - El siglo de la investigación. Barcelona: Labor, 1966.

WEHNER, W. - História de a criminología. Barcelona: Zeus, 1964. 